\title{
Procedural justice and its role in promoting voluntary compliance
}

\author{
Kristina Murphy ${ }^{\uparrow}$
}

\section{Introduction}

Why do people obey the law, and what can authorities do to encourage people to comply voluntarily with the law? These questions have received interest from regulators and scholars interested in understanding the motivators of law-abiding behaviour. This chapter addresses these two questions. It first discusses different perspectives on why people obey the law and it then proceeds to discuss in detail the growing interest in procedural justice-based approaches to regulation. The chapter puts forward that people can be rational actors motivated solely by personal gain or they can be moral actors motivated to obey authorities and laws because of an intrinsic obligation to do the right thing. Research across a variety of regulatory contexts has revealed that the latter form of compliance can be fostered when authorities use procedural justice. The key ideas and controversies in the procedural justice literature will also be presented, followed by a discussion of future directions in the field.

$1 \quad$ Email: t.murphy@griffith.edu.au. 


\section{Why do people comply with the law?}

Laws are established to control human behaviour, and regulatory authorities are put in place to enforce those laws. For a well-functioning society, we need people to comply with the law and to follow the directions of those who enforce the law. A longstanding debate has existed in the literature between those who believe people obey the law only when confronted with harsh sanctions and penalties and those who believe people obey the law because it is right and just to do so (Tyler 1990). The former perspective on compliance is instrumental in its focus while the latter perspective is normative in its focus. This dichotomy resonates with Valerie Braithwaite's discussion in the previous chapter of compliance being driven by both outcome and process.

The basic premise of the instrumental model of compliance is that people are motivated to maximise their own personal gains; they are rational actors who behave in a manner that personally benefits them. Individuals are thought to assess opportunities and risks and will disobey the law when the anticipated fines and probability of being caught for noncompliance are small in relation to the profits to be made through noncompliance. The view is that if compliance is a rational choice, authorities should respond by deterring individuals from acts of noncompliance by ensuring the benefits to be obtained through noncompliance are much lower than those obtained through compliance (Becker 1968). Advocates of this perspective suggest that compliance can be best achieved in two ways: 1) by increasing the probability of detecting noncompliers; and 2) by increasing sanctions to the point where noncompliance becomes irrational. According to this deterrencebased approach to regulation, authorities need to find an appropriate balance between these two measures to make compliant behaviour the rational choice. This instrumental perspective of human behaviour underpins many of the enforcement policies adopted by regulators.

The problem with such an instrumental perspective of behaviour, however, is that it can only ever give a partial explanation for why people obey the law. Deterrents may prevent noncompliance, but they cannot explain why people obey the law in the absence of deterrence. We know from the work undertaken at the Centre for Tax System Integrity (CTSI) at RegNet (1999-2005), for example, that taxpayers 
often complied with their tax obligations despite the fact that the odds of detection and penalties for noncompliance were low. In other words, deterrence is less helpful for explaining why people obey laws voluntarily.

The normative perspective of compliance, in contrast, suggests that people comply with the law not because of a fear of the consequences they may face for noncompliance, but because they see the law as right and just and feel a moral obligation to obey the law (see Tyler 1990). Here, compliance is therefore voluntary in nature because it occurs in the absence of deterrents. Research has supported the idea that law compliance is motivated more often by normative concerns borne out of the perceived legitimacy of the system than by instrumental concerns. In his influential study, Tyler (1990) found that people reported being compliant with laws because the laws aligned with their morals about what was right and just. Tyler also found that these internal morals influenced people's compliance behaviour more so than the perceived risk of detection or sanctions for wrongdoing.

It is appealing to think of most people as committed moral actors motivated to comply with the law out of a sense of obligation to do right (Braithwaite, Chapter 2, this volume), but what happens if the law contravenes an individual's morals? What if the law is seen to be inconsistent with what an individual sees as right and just? This might lead to a situation where a person becomes resistant to authority and its laws or feels justified breaking the law. This situation points to the crucial role that authorities can also play in securing voluntary compliance. Importantly, research has revealed that compliance can also be influenced by how a person views an authority charged with enforcing the law. Tyler (1990) again has shown that the perceived legitimacy of an authority is key to securing compliance with laws that might be incompatible with an individual's morals. Legitimacy reflects the degree to which people recognise the right of an authority to govern their behaviour. If people view an authority as legitimate, they agree that the authority has the right to govern them. Providing an authority with legitimacy transfers to them the authority and right to define what constitutes acceptable forms of behaviour. As such, citizens will be more willing to defer to a legitimate authority's laws even if they may not like the law they are obeying.

The fact that the perceived legitimacy of an authority can also promote voluntary compliance behaviour, even when people view a law itself as unjust, is important because authorities are able to directly shape the way 
in which people view them. Some of the taxation and policing research undertaken at RegNet suggests that an authority's legitimacy can be built through the way in which authorities yield their power (Hinds and Murphy 2007; Murphy 2005). Tyler (1990) argues that authorities that govern with procedural justice will be better able to foster voluntary compliance and will have to rely less heavily on deterrence. Regulators are often unable to change unpopular laws but they are able to change the way they treat those they are charged with regulating. This makes procedural justice an appealing and valuable tool for promoting voluntary compliance.

\section{What is procedural justice?}

In the social-psychological literature, procedural justice is conceptualised as involving the quality of treatment and quality of decision-making received by an authority. It involves more than a regulator just being nice to people. Criteria typically used to define procedurally just treatment include respect, neutrality, trustworthiness and voice. Respect refers to whether the authority is respectful and polite in their dealings with a person, and also whether they respect people's rights under the law. If they treat people with dignity and are respectful in how they issue orders or enforce laws then people will view them as more procedurally fair. Research has found that people are particularly sensitive to the way in which authorities issue directives, with disrespectful treatment being shown to produce reactance and negative evaluations of the authority (Murphy 2004). Neutrality involves making decisions based on consistently applied legal rules and principles and the facts of a case, not on personal opinions and biases. People want to feel assured that authorities are treating them in the same way as any other individual in society. Transparency or openness about how decisions are being made also facilitates the belief that decision-making procedures are neutral. An authority's trustworthiness is an indicator of whether the authority will be motivated to treat a person in a fair manner. People react favourably to the judgement that an authority they are interacting with is benevolent and caring and is sincerely trying to do what is best for the people with whom they deal. Authorities communicate their trustworthiness and fairness when they listen to people's accounts and explain or justify their actions in ways that show an awareness of and sensitivity to people's needs and concerns. Finally, voice is important to individuals. People value having the opportunity to voice concerns 
and issues to an authority before a decision is made in their case. If an authority then takes these concerns into account in the decision-making process, people will be left feeling that they have received procedural justice. Resistance can be allayed through providing regulatees a voice (see also Braithwaite, Chapter 2, this volume). Giving an individual a real voice, however, requires that an authority genuinely commits to acting on any valid concerns that may be raised. Ignoring an individual's grievances or concerns is unlikely to foster a sense that the authority has used procedural justice. In summary, then, if individuals are treated respectfully by an authority, are dealt with in an unbiased fashion, believe the authority has demonstrated trustworthy motives and has taken the individual's concerns into account before reaching a decision then individuals will evaluate the interaction as more procedurally just.

There has been a plethora of studies published that demonstrate how procedural justice can build legitimacy and promote voluntary compliance with both authority directives and laws. The majority of these studies use self-report survey methodologies to show that people who view their experience with an authority to be more procedurally just are much more likely to view the authority as having legitimacy (for example, Hinds and Murphy 2007; Murphy et al. 2008; Sunshine and Tyler 2003; Tyler 1990). Many of these studies also find a direct link between procedural justice evaluations and subsequent self-reported compliance behaviours, or they find that procedural justice shapes compliance indirectly through the mediating influence of legitimacy (Sunshine and Tyler 2003; Murphy et al. 2008; Murphy 2005). While much of this research has been undertaken within a policing context, similar findings have been obtained across a number of different regulatory contexts, including in prisons, in taxation regulation and in nursing home regulation, to name a few (for example, Braithwaite and Makkai 1994; Reisig and Mesko 2009; Murphy 2004, 2005; Wenzel 2006). Studies that use observational or interview methodologies reveal similar findings to survey studies. For example, McCluskey's (2003) observational research showed how interactions between police and the public were less likely to result in defiance towards officers and were less likely to escalate to violence if police officers used procedural justice when initially dealing with individuals. Authorities often have to deliver unfavourable decisions or outcomes, yet even if an outcome is unfavourable, research has demonstrated that people will still be more likely to accept those decisions and will be more likely to comply if the authority has delivered that outcome in a procedurally just way (Tyler 1990). 


\section{Theories of procedural justice}

With empirical evidence consistently showing that procedural justice has beneficial effects on promoting an authority's legitimacy and people's willingness to comply with the law, understanding the theoretical mechanisms that explain why this occurs is important. Early theorising in the field suggested that procedural justice mattered to people because it was able to maximise their instrumental gains. This instrumental perspective on procedural justice can be traced back to the seminal work of Thibaut and Walker (1975). Their 'process control' theory was developed after observing the way in which disputants who were party to a formal grievance evaluated the authorities that made decisions in their case, and it focused on the degree to which people were able to exert influence over the authority's decisions. Thibaut and Walker posited that if people felt they had control over decisions pertaining to their dispute, they would believe the procedures arriving at those decisions had been just. In contrast, if people felt they lacked control over the final outcome of their case, they were more likely to believe the process had been unjust. In this particular theory, voice and control were of particular concern to people. If they felt they were able to voice concerns and that voice was able to shape the outcome of their case then they evaluated the experience as more just.

Later theories in the field steered away from this instrumental view of procedural justice. Instead, the next wave of theories suggested that procedural justice mattered to people because it conveyed important symbolic messages about a person's identity, value and status in society. Social identity thus comprised the core theoretical mechanism explaining why procedural justice had the effects on people that it did. And, indeed, work undertaken by Wenzel (2002) from the CTSI revealed the importance of identity processes in shaping how individuals respond to justice concerns. The 'group engagement' and 'group value' models specifically incorporate these notions of identity to explain the relationship between procedural justice, legitimacy and compliance (see Blader and Tyler 2009; Lind and Tyler 1988). These identity-based explanations have dominated theorising in the field and they provide a way of understanding the dynamics of power relationships within social groups. Specifically, they attempt to explain why people comply with group laws and internalise group values. These theories suggest that the experience of receiving procedural justice from authority figures has positive effects on perceptions of legitimacy and on compliance 
behaviour because such experiences strengthen people's connections to the social groups that the authorities represent. This in turn promotes allegiance to group norms and values and encourages compliance with the law (Blader and Tyler 2009). In other words, receiving procedurally just treatment from an authority communicates to people that authorities respect them and see them as worthwhile members of the community. This promotes greater identification with the community by generating a positive sense of the individual's place in society and leads the person to feel more committed to doing right by the authority who represents that community. Hence, people are motivated to legitimate the authority of groups within which they feel status and standing. They feel they should support the authority of the groups to which they belong and they internalise the value that they should obey the authority of a group with which they identify (Bradford et al. 2014).

More recent theorising in the field highlights the added importance of emotion for understanding the effect of procedural injustice on legitimacy and noncompliance. Murphy and her colleagues have acknowledged the value and importance of identity, but they have posited that both identity and emotion should be included within one explanatory framework to fully understand how, when and why procedural justice works as it does. In other words, perceptions of an authority's legitimacy, in addition to emotional experiences and identity processes, need to be considered together to fully understand the different effects that procedural justice can have on different people across different contexts. Using empirical data, Murphy and her colleagues demonstrated how unjust treatment by authorities could elicit negative emotions in individuals (for example, Murphy and Tyler 2008; Barkworth and Murphy 2015). These negative emotional reactions subsequently produced a variety of retaliatory behaviours in response to unfair treatment, including reactance, defiance towards authorities and subsequent noncompliance with the law. The idea that authorities can have an impact on people's emotions is not new. There is a long tradition in the criminology literature showing how injustices can elicit negative emotions (for example, Sherman 1993; Braithwaite 1989; see also Harris, Chapter 4, this volume). What is new in Murphy's work is the attempt to merge theories of emotion with theories of identity to produce a more sophisticated theory of procedural justice. 
Murphy argues that events (for example, being regulated or punished) can be appraised as either harmful or favourable to an individual's personal goals or desires. Here, emotions can be experienced in response to such appraisals. Anger, it is argued, results from an appraisal that another person or group is harming or threatening the self. This can result in retaliatory action as a person attempts to protect their identity and self from the harm. Unfair treatment from an authority could be one such threat to a person's sense of self (Braithwaite, Chapter 2, this volume). Such treatment can lead individuals to perceive their identity and standing in a group are being threatened. This identity threat can produce a negative emotional response that in turn results in destructive thoughts and behaviours. Hence, Murphy proposes that when unfair treatment threatens one's identity, negative emotion may result. If negative emotion is then not managed appropriately it has the potential to lead people to question the legitimacy of an authority or can lead to retaliatory behaviour and noncompliance with authorities and laws. Studies testing the validity of an emotion-based theory of procedural justice are only in their infancy, but findings thus far appear to support the value of considering legitimacy, emotion and identity in one explanatory model.

\section{Controversies in the field}

The discussion presented earlier suggests that procedural justice is a useful tool for authorities wishing to promote their own legitimacy and to encourage people to voluntarily comply with the law. Despite the apparent success of procedural justice, however, research in the field is not without its limitations. Several continuing controversies with this body of research remain. Three of these controversies will be highlighted followed by a brief discussion of new research agendas that have attracted attention in the field.

Measurement issues represent one recurring controversy in the field. A number of scholars have argued that procedural justice research inconsistently operationalises key constructs and has done little to evaluate the construct validity of existing scales (for example, Gau 2011; Reisig et al. 2007; Johnson et al. 2014). These authors have noted that measures of procedural justice and police legitimacy have differed from one study to the next. Concern has also been raised about whether measured variables actually reflect different concepts. For example, 
it has been argued that commonly used procedural justice measures often overlap with measures used to construct legitimacy. If measures are inconsistent or do not measure what is intended, it can lead to misleading and inaccurate conclusions across different studies.

Second, Tankebe (2009a) has noted that the procedural justice literature has tended to overemphasise the relationship between procedural justice and compliance, and has tended to underemphasise the role of instrumental factors such as outcome favourability or authority effectiveness in shaping people's compliance behaviour. Tankebe used research from the field of restorative justice to demonstrate his point. He noted that many restorative justice studies fail to find long-term effects in reducing reoffending. Offenders participating in restorative justice conferences tend to rate their experience as more procedurally just than those who attend traditional courts. Hence, one would expect long-term changes in compliance to occur among participants involved in restorative justice conferences if claims made in the procedural justice literature are valid. In fact, many procedural justice studies that purport to examine compliance behaviour do so using self-report measures of compliance. In those studies, procedural justice is typically found to be linked to compliance, yet the conclusions are more mixed when objective measures of compliance are used, as is the case in restorative justice studies.

With respect to Tankebe's (2009a) second issue, it has been noted that procedural justice scholars tend to underemphasise the importance of instrumental factors in shaping people's views and behaviours. For example, when compared with American and UK-based research, Australian procedural justice policing research finds that citizens often place much greater weight on the effectiveness of authorities when judging their legitimacy or when predicting their cooperation (Hinds and Murphy 2007; Sargeant et al. 2014). While procedural justice still dominates most Australians' assessments of the legitimacy of authorities, such findings do suggest that researchers should not discount the importance of instrumental concerns. In fact, in research from Ghana- a country characterised by the widespread corruption of regulatory authorities-it has been found that citizens are more likely to view authorities as legitimate or are more likely to cooperate with them if the authorities are viewed to be effective in their job, with procedural justice playing little role in predicting their compliance behaviour or assessments of an authority's legitimacy (Tankebe 2009b; for similar 
findings across different regulatory contexts, see Murphy 2009; Murphy and Barkworth 2014; Sargeant et al. 2014). Hence, context appears to matter and researchers should not underestimate the potential effect that instrumental factors, in addition to procedural justice, have in shaping people's compliance behaviour and views of authorities.

The third major criticism raised in relation to the procedural justice literature is the tendency for some regulators and researchers to overemphasise the value of procedural justice for securing cooperation and compliance, rather than promoting it as a good in itself (Tankebe 2009a). Regulators have an obligation to exercise their authority in a procedurally fair way, irrespective of any instrumental benefit such an approach may have in facilitating their role in maintaining compliance. This needs to be kept in mind when advocating a procedural justicebased approach to regulation.

\section{Future research directions}

It is important to highlight at this stage in the chapter that the majority of new studies published in the procedural justice literature simply aim to replicate existing studies in the field. The concern with this type of research is that the procedural justice literature risks becoming stale, failing to push the boundaries or challenge the key assertions put forth in the existing literature. This is what made the procedural justice work coming out of RegNet so appealing; it sought to push the boundaries in theory development. What is needed for the future of procedural justice scholarship is research that adopts new methodologies or that seeks to better understand the contexts where procedural justice works more or less effectively or why it works as it does. In terms of future directions for the field, therefore, there are a few developments that have occurred in the past five years that offer important avenues for extending research in the field. These developments include: 1) more sophisticated theorising around the concept of legitimacy; 2) extending existing theoretical frameworks to better understand when, how and why procedural justice works; and 3) utilisation of innovative methodologies to understand the effect of procedural justice in practice.

\section{Reconceptualising legitimacy}

Legitimacy has typically been conceptualised in the procedural justice literature as people's 'obligation to obey' an authority and by the perceived 'institutional trust' of an authority. Tyler's (1990) measures 
of 'obligation to obey' and 'institutional trust' feature prominently in most of the empirical research on perceived legitimacy. Recently, however, Tankebe (2013) offered an alternative conceptualisation of legitimacy, arguing against equating legitimacy with a felt obligation to obey authorities. Tankebe (2013) posits that legitimacy comprises four components: distributive justice (that is, the equal distribution of services across groups), procedural justice, authority lawfulness and authority effectiveness. While Tyler treats procedural justice as an antecedent of legitimacy, Tankebe considers it a component of legitimacy. Moreover, Tankebe (2013) treats obligation to obey as a consequence of legitimacy, rather than it being a component of legitimacy, as originally conceptualised by Tyler.

Jackson et al. (2012) also suggest that legitimacy entails more than just trust and obligation to obey. They have recently defined and measured police legitimacy as a multidimensional concept with three interlinked elements: 1) obligation to obey; 2) moral alignment; and 3) legality. Obligation to obey is consistent with Tyler's definition of legitimacy, with a legitimate authority able to garner obedience from the public. Moral alignment reflects the belief that authorities and the public share broadly similar moral positions about appropriate law-abiding behaviour. Legality reflects whether authorities themselves follow their own rules (similar to Tankebe's authority lawfulness concept). If authorities are seen by the public to be acting in an ethical manner or exercising their authority according to established principles, they will be seen as legitimate.

The reconceptualisation of legitimacy shows much promise as a future research direction. By exploring empirically the link between these different proposed notions of legitimacy, future research can begin to tease apart the separate roles that each might play in explaining compliance behaviour.

\section{Extending theory}

As noted earlier, the group value and group engagement models have dominated theorising in the procedural justice field. Very few scholars have attempted to offer alternative models or to extend theories in the field, opting instead to utilise existing theories. Murphy has perhaps been one of the few recent procedural justice scholars to offer an alternative perspective to the dominant identity-based theories, suggesting that researchers should consider the role of emotion in 
addition to identity and legitimacy to understand how, when and why procedural justice works as it does (see the discussion earlier explaining this new perspective). Future researchers should consider whether the inclusion of this emotion perspective represents a more valid and reliable explanation for procedural justice effects or whether other alternative theoretical explanations may offer more reliable explanations for the procedural justice effect across different contexts and groups. One such example is Valerie Braithwaite's motivational posturing theory of defiance (Braithwaite, Chapter 2, this volume; see also Murphy 2016).

\section{Innovative methodologies}

Finally, a burgeoning area of study in the procedural justice field, and one that offers another fruitful avenue for future research, has involved researchers working closely with regulators to evaluate procedural justice effects in applied settings using randomised controlled field trials. The limitation with many of the other methodologies commonly used in the procedural justice field - that is, survey research, observation and interview methods-is that the causal relationships between the key variables of interest are difficult to establish. Randomised controlled field trials allow researchers to directly manipulate one variable (in this case, procedural justice) to explore its effect on a range of other variables (for example, can introducing procedural justice change how people evaluate police?). By randomly allocating people into different groups to experience a manipulation differently - that is, a control versus an experimental group-this allows direct causal testing of the effect of procedural justice on the public's views and behaviour.

A few notable scholars have made use of randomised controlled field trials to evaluate whether authorities can be trained to use procedural justice and whether this has beneficial effects on the public's behaviour and their perceptions of those authorities (for example, Mazerolle et al. 2012, 2013, 2014; Murphy et al. 2014; Wenzel 2006; Wheller et al. 2013). Of the limited number of studies that exist, researchers have typically found that members of the public who have interactions with procedurally just authorities - that is, those exposed to the experimental condition - are significantly more likely to evaluate those authorities positively and are more willing to display cooperative and compliant behaviours compared with people exposed to the control condition. While there are likely to be more fruitful developments that arise, these three directions are currently receiving attention in the field. 


\section{Conclusion}

To conclude, procedural justice appears to have an important role to play in regulatory practice. Procedural justice can improve people's willingness to cooperate with authorities and it can encourage them to voluntarily comply with the law. This is because procedural justice can promote identification with authorities and reduce negative emotion and resistance. It can also build public perceptions of the legitimacy of authorities, leaving people to feel more obligated to obey their instructions and laws.

\section{Further reading}

Mazerolle, L, Sargeant, E, Cherney, A, Bennett, S, Murphy, K, Antrobus, $\mathrm{E}$ and Martin, P 2014. Procedural Justice and Legitimacy in Policing. Switzerland: Springer Briefs. doi.org/10.1007/978-3-319-04543-6.

Tyler, TR 2006. Why People Obey the Law. Princeton, NJ: Princeton University Press.

\section{References}

Barkworth,J and Murphy, K 2015.'Procedural justice policing and citizen compliance behaviour: The importance of emotion', Psychology, Crime and Law 21: 254-73. doi.org/10.1080/1068316X.2014.951649.

Becker, G 1968. 'Crime and punishment: An econometric approach', Journal of Political Economics 76: 169-217. doi.org/10.1086/259394.

Blader, S and Tyler, TR 2009. 'Testing and expanding the group engagement model', Journal of Applied Psychology 94: 445-64. doi. org/10.1037/a0013935.

Bradford, B, Murphy, K and Jackson, J 2014. 'Officers as mirrors: Policing, procedural justice and the (re)production of social identity', British Journal of Criminology 54: 527-50. doi.org/10.1093/bjc/azu021.

Braithwaite, J 1989. Crime, Shame and Reintegration. Cambridge: Cambridge University Press. doi.org/10.1017/CBO9780511804618. 
Braithwaite, J and Makkai, T 1994. 'Trust and compliance', Policing and Society 4: 1-12. doi.org/10.1080/10439463.1994.9964679.

Gau, J 2011. 'The convergent and discriminant validity of procedural justice and police legitimacy: An empirical test of core theoretical propositions', Journal of Criminal Justice 39: 489-98. doi.org/ 10.1016/j.jcrimjus.2011.09.004.

Hinds, L and Murphy, K 2007. 'Public satisfaction with police: Using procedural justice to improve police legitimacy', Australian and New Zealand Journal of Criminology 40: 27-42. doi.org/10.1375/ acri.40.1.27.

Jackson, J, Bradford, B, Hough, M, Myhill, A, Quinton, P and Tyler, TR 2012. 'Why do people comply with the law? Legitimacy and the influence of legal institutions', British Journal of Criminology 52: 1051-71. doi.org/10.1093/bjc/azs032.

Johnson, D, Maguire, E and Kuhn, J 2014. 'Public perceptions of the legitimacy of the law and legal authorities: Evidence from the Caribbean', Law and Society Review 48: 947-78. doi.org/10.1111/ lasr.12102.

Lind, EA and Tyler, TR 1988. The Social Psychology of Procedural Justice. New York: Plenum Press. doi.org/10.1007/978-1-4899-2115-4.

McCluskey, J 2003. Police Requests for Compliance: Coercive and Procedurally Just Tactics. New York: LFB Scholarly.

Mazerolle, L, Antrobus, E, Bennett, S and Tyler, TR 2013. 'Shaping citizen perceptions of police legitimacy: A randomized field trial of procedural justice', Criminology 51: 33-63. doi.org/10.1111/ j.1745-9125.2012.00289.x.

Mazerolle, L, Bennett, S, Antrobus, E and Eggins, L 2012. 'Procedural justice, routine encounters and citizen perceptions of police: Main findings from the Queensland Community Engagement Trial (QCET)', Journal of Experimental Criminology 8: 343-67. doi. org/10.1007/s11292-012-9160-1.

Mazerolle, L, Sargeant, E, Cherney, A, Bennett, S, Murphy, K, Antrobus, $\mathrm{E}$ and Martin, P 2014. Procedural Justice and Legitimacy in Policing. Switzerland: Springer Briefs. doi.org/10.1007/978-3-319-04543-6. 
Murphy, K 2004. 'The role of trust in nurturing compliance: A study of accused tax avoiders', Law and Human Behavior 28: 187-209. doi. org/10.1023/B:LAHU.0000022322.94776.ca.

Murphy, K 2005. 'Regulating more effectively: The relationship between procedural justice, legitimacy and tax non-compliance', Journal of Law and Society 32: 562-89. doi.org/10.1111/j.1467-6478.2005.00338.x.

Murphy, K 2009. 'Public satisfaction with police: The importance of procedural justice and police performance in police-citizen encounters', Australian and New Zealand Journal of Criminology 42: 159-78. doi.org/10.1375/acri.42.2.159.

Murphy, K 2016. 'Turning defiance into compliance with procedural justice: Understanding reactions to regulatory encounters through motivational posturing', Regulation and Governance 10: 93-109. doi. org/10.1111/rego.12073.

Murphy, K and Barkworth, J 2014. 'Victim willingness to report crime to police: Does procedural justice or outcome matter most?', Victims and Offenders 9: 178-204. doi.org/10.1080/15564886.2013.872744.

Murphy, K and Tyler, TR 2008. 'Procedural justice and compliance behaviour: The mediating role of emotions', European Journal of Social Psychology 38: 652-68. doi.org/10.1002/ejsp.502.

Murphy, K, Hinds, L and Fleming, J 2008. 'Encouraging public cooperation and support for police', Policing and Society 18: 138-57. doi.org/10.1080/10439460802008660.

Murphy, K, Mazerolle, L and Bennett, S 2014. 'Promoting trust in police: Findings from a randomized experimental field trial of procedural justice policing', Policing E' Society 24: 405-24. doi.org/10.1080/104 39463.2013.862246.

Reisig, M and Mesko, G 2009. 'Procedural justice, legitimacy and prisoner misconduct', Psychology, Crime and Law 15: 41-59. doi. org/10.1080/10683160802089768.

Reisig, M, Bratton, J and Gertz, M 2007. 'The construct validity and refinement of process-based policing measures', Criminal Justice and Behavior 34: 1005-28. doi.org/10.1177/0093854807301275. 
Sargeant, E, Murphy, K and Cherney, A 2014. 'Ethnicity, trust and cooperation with police: Testing the dominance of the process based model', European Journal of Criminology 11: 500-24. doi. org/10.1177/1477370813511386.

Sherman, L 1993. 'Defiance, deterrence and irrelevance: A theory of the criminal sanction', Journal of Research in Crime and Delinquency 30: 445-73. doi.org/10.1177/0022427893030004006.

Sunshine, J and Tyler, TR 2003. 'The role of procedural justice and legitimacy in shaping public support for policing', Law and Society Review 37: 513-47. doi.org/10.1111/1540-5893.3703002.

Tankebe, J 2009a. 'Policing, procedural fairness and public behavior: A review and critique', International Journal of Police Science and Management 11: 8-19. doi.org/10.1350/ijps.2009.11.1.105.

Tankebe, J 2009b. 'Public cooperation with the police in Ghana: Does procedural justice matter?', Criminology 47: 1265-93. doi. org/10.1111/j.1745-9125.2009.00175.x.

Tankebe, J 2013. 'Viewing things differently: The dimensions of public perceptions of police legitimacy', Criminology 51: 103-35. doi. org/10.1111/j.1745-9125.2012.00291.x.

Thibaut J and Walker, L 1975. Procedural Justice: A Psychological Analysis. Hillsdale, NJ: Lawrence Erlbaum.

Tyler, TR 1990. Why People Obey the Law. New Haven, Conn.: Yale University Press.

Wenzel, M 2002.'The impact of outcome orientation and justice concerns on tax compliance: The role of taxpayers' identity', Journal of Applied Psychology 87: 629-45. doi.org/10.1037/0021-9010.87.4.629.

Wenzel, M 2006. 'A letter from the tax office: Compliance effects of informational and interpersonal justice', Social Justice Research 19: 345-64. doi.org/10.1007/s11211-006-0011-y.

Wheller, L, Quinton, P, Fildes, A and Mills, P 2013. The Greater Manchester Police Procedural Justice Training Experiment. London: College of Policing. 
This text is taken from Regulatory Theory: Foundations and applications, edited by Peter Drahos, published 2017 by ANU Press, The Australian National University, Canberra, Australia. 